This is a pre-print of an article published in Polymer Testing, 52 (2016) 46-53. The final version is available online at: https://doi.org/10.1016/j.polymertesting.2016.03.025

\title{
Influence of thermal and UV treatment on the polypropylene/graphite composite
}

\author{
P. Vilímová ${ }^{1}$, J. Tokarský $^{1,2}$, P. Peikertová ${ }^{1,2}$, K. Mamulová Kutláková ${ }^{1}$, T. Plaček ${ }^{3}$ \\ ${ }^{1}$ Nanotechnology centre, VŠB-TUO, 17. listopadu 15, 70833 Ostrava, Czech Republic \\ ${ }^{2}$ IT4Innovations Centre of Excellence, VŠB-TUO, 17. listopadu 15, 70833 Ostrava, Czech Republic \\ ${ }^{3}$ FMMI, VŠB-TUO, 17. listopadu 15, 70833 Ostrava, Czech Republic
}

\begin{abstract}
Electrically conductive polypropylene/graphite (PP/graphite) composites were prepared via blending granulated PP with maleic anhydride grafted PP and natural graphite. Electrical conductivity of prepared samples containing either 65,70 , or 75 wt.\% of graphite was measured and the most conductive sample containing 75 wt.\% of graphite was exposed to UV irradiation for 1 and 24 hours or thermally treated at $170{ }^{\circ} \mathrm{C}$ for 1 hour. The influence of thermal and UV exposure on the structural and electrical changes in such treated samples was studied. Local current measurements on the surface were made using scanning spreading resistance microscopy and morphology of the surface was studied by atomic force microscopy. X-ray diffraction analysis, infrared and Raman spectroscopy were also used for the structural characterization. Properties of treated and untreated samples are compared and differences are discussed.
\end{abstract}

Keywords: polymer, composite, graphite, polypropylene, conductivity, scanning spreading resistance microscopy

\section{Introduction}

Polymer composites are the promising group of synthetic materials containing at least two phases: matrix and filler. Combination of polymer matrix with different kinds of organic and inorganic fillers leads to improved properties of resulting composite. These materials are of great scientific and technological interest and are used in various applications like aerospace and automotive structures, or marine and sports goods, to name a few [1-6].

Polypropylene (PP) belongs to the group of the thermoplastic polymers offering excellent mechanical properties and electrical and chemical resistance against higher temperatures. PP can be modified using a variety of fillers reinforcements to yield specific properties [7-10]. Interfacial adhesion between fillers and PP matrix is one of the key factors determining the properties and structure of resulting composites. Maleic anhydride (MAH) is very suitable for this purpose and MAH-grafted PP (MAH-g-PP) is used to improve polarity, compatibility and interaction of PP with other materials, especially fillers. For detailed description of the necessity of using MAH-g-PP together with pure PP the reader is referred to [11-12].

Graphite, carbon material exhibiting exceptional electrical transport properties, is widely used as conductive filler. Natural graphite is found in the form of flakes composed of layers with a $c$-axis lattice constant of $0.67 \mathrm{~nm}$. In graphite layer, carbon atoms are strongly bonded by 
covalent bonds while layers are bound only by weaker van der Waals forces causing highly anisotropic properties. Along the basal plane the natural graphite is the excellent thermal and electrical conductor with low coefficient of thermal expansion and very high Young's modulus. Because of these properties and very low cost, natural graphite is very often used as the reinforcing component in the composites and considerable amount of studies focused on PP composites reinforced with graphite have been published [13-19]. Conductivity is the fundamental property of this type of material and may be negatively affected by changes of the ambient conditions. This fact limits application of these materials.

Király and Ronkay [20] studied the changes of conductivity of PP/graphite composites containing $22-62.8$ wt. $\%$ of graphite filler in the temperature range $-20-130{ }^{\circ} \mathrm{C}$. Their study showed negative influence of increased temperature on the conductivity. The same result was presented by Tchmutin et al. [21]. They studied PP/graphite composites containing $8-40$ wt. $\%$ of graphite filler and for samples containing 10 wt. $\%$ and 18 wt. $\%$ of graphite filler the measurement of conductivity took place in the range of temperature $0-110^{\circ} \mathrm{C}$. In both studies the connection between the decrease in conductivity and thermal expansion of polymer matrix is discussed. With increasing temperature the polymer matrix can reduce the contact conducting area between the graphite. This main fact results in the decrease of conductivity.

Present work is focused on the polymer composite with PP matrix and natural graphite filler (PP/graphite). The main aim of this paper is to describe the UV and thermal influence on the conductivity, morphology, and the structure of the PP/graphite. The UV and thermally treated samples were extensively studied using the wide range of the instrumental analytic methods. The Martens hardness and macroscopic conductivity of PP/graphite composites was measured and also scanning spreading resistance microscopy (SSRM) was used for detection of the surface conductivity in the nanoscale. The changes in the morphology of the surface were studied by atomic force microscopy (AFM). The structural characteristics were measured using X-ray diffraction (XRD) analysis, infrared and Raman spectroscopy.

\section{Experimental}

\subsection{Materials}

The natural graphite powder serving as the filler was purchased from Graphite Týn s.r.o., Czech Republic (purity $>99.5 \%, \mathrm{BET}=3 \mathrm{~m}^{2} / \mathrm{g}$ ). The commercial grade PP used as the polymer matrix was supplied from Yung Chia Chemical Ind., Co., Ltd., Taiwan. The $\mathrm{PP} /$ graphite composites was prepared at the Tsinghua University, China.

\subsection{Sample preparation}

A weighted amount ( $\mathrm{m}=3 \mathrm{~g})$ of granulated PP (85 wt.\%) and MAH-g-PP (15 wt.\%) containing mixture was transferred into the round-bottom flask with $300 \mathrm{ml}$ of xylene. The mixture (i.e., PP and MAH-g-PP) was slowly heated to $130{ }^{\circ} \mathrm{C}$ until it dissolved completely. Further, three different amounts $(65,70,75 \mathrm{wt} . \%)$ of the natural graphite as the filler were added. Compositions of the resulting composites were as follows: $65 \mathrm{wt} . \%$ of graphite + 29.75 wt. $\%$ of PP +5.25 wt. $\%$ of MAH-g-PP, 70 wt. $\%$ of graphite +25.5 wt. $\%$ of PP +4.5 wt. $\%$ of MAH-g-PP, and 75 wt. $\%$ of graphite +21.25 wt. $\%$ of PP +3.75 wt. $\%$ of MAH-g-PP. After 3 hours, the temperature was lowered to $45{ }^{\circ} \mathrm{C}$ and the mixture was transferred into 
excess of acetone (about $1500 \mathrm{ml}$ ), where composites started to precipitate. Precipitated composites were washed three times with acetone and dried at $60{ }^{\circ} \mathrm{C}$ for $12 \mathrm{~h}$. The coarsegrained mixture was grinded in the High Speed Disintegrator at $29000 \mathrm{rpm}$ for 5 minutes. The obtained powdered mixture was processed by compression molding: the composites were molded in $100 \times 15 \times 1.5 \mathrm{~mm}$ bar with a hot press at a temperature of $180^{\circ} \mathrm{C}$ and a pressure of 8 MPa for 5 minutes.

\subsection{Measurement of macroscopic electrical conductivity}

For measurement of electrical conductivity the special measuring apparatus (Fig. 1) was used. Conductivity of samples has been measured by static applied voltage $(1.000 \pm 0.001 \mathrm{~V})$ in DC regime. The distance between the measuring $\mathrm{Cu}$-electrodes with a triangular cross-section was $47 \mathrm{~mm}$. DC voltage source (DC POWER SUPPLY HY 3003 D-2) was annexed with the endurance of tens of seconds to minutes. Electric current passing through the samples has been measured for time interval 60 seconds. Conductivity was calculated from the mean value of electric current. Multimeter AGILENT 34401A and V-meter UNI-T UT802 were used for the calibration. Parameters of measurement were controlled using computer equipped with PCI-6221 board. Obtained data were registered and processed in the original homemade software prepared in LabVIEW.

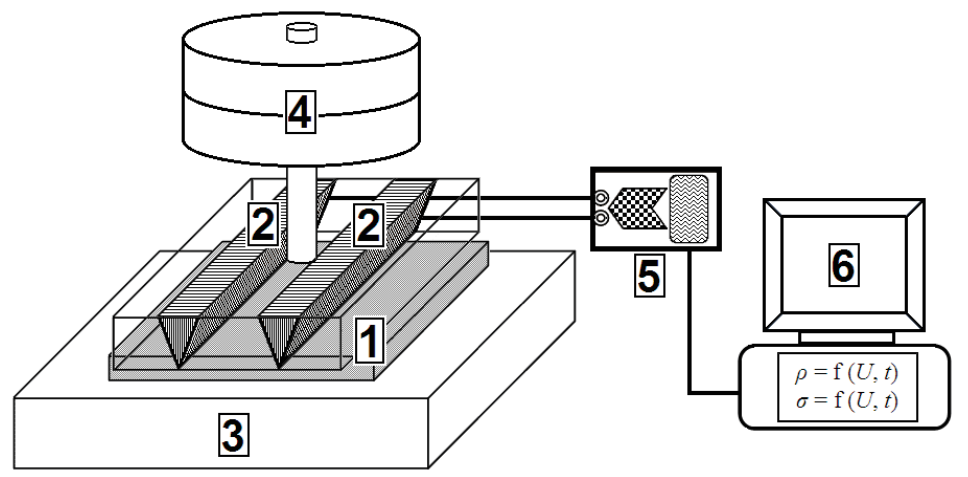

Fig. 1. Experimental apparatus for measurement of electrical conductivity. 1) $\mathrm{PP} /$ graphite sample 2) $\mathrm{Cu}-$ electrodes (distance $47 \mathrm{~mm}$ ); 3) flexible insulator; 4) weights to ensure a constant load; 5) measuring card; 6) PC + software.

\subsection{Martens hardness test}

Martens hardness of original and modified composites was examined by testing machine ZWICK ZHU/2.5. Tungsten carbide ball with diameter $6.34 \mathrm{~mm}$ was used as the indentor and operating loads of $100 \mathrm{~N}$ was selected for this test.

\subsection{Thermal treatment}

Sample was exposed to temperature $170{ }^{\circ} \mathrm{C}$ for 1 hour in the laboratory drier Memmert UNE 300. After heating, the sample was taken out of the drier and allowed to cool freely to the room temperature. Sample was denoted as PP/graphite_170/1.

\subsection{UV irradiation}

Samples were irradiated by UV light for 1 hour (sample denoted as PP/graphite_UV/1) and 24 hours (sample denoted as PP/graphite_UV/24) using lamp source containing UVB component (Narva LT 36W/073 Blacklight blue). Light spectrum of this lamp is shown in Fig. 2. Temperature of the sample after 24 hours of UV irradiation was $\sim 40{ }^{\circ} \mathrm{C}$ (temperature in laboratory was $\sim 25^{\circ} \mathrm{C}$ ). After 1 hour, an increase in temperature was negligible. 
This is a pre-print of an article published in Polymer Testing, 52 (2016) 46-53. The final version is available online at: https://doi.org/10.1016/j.polymertesting.2016.03.025

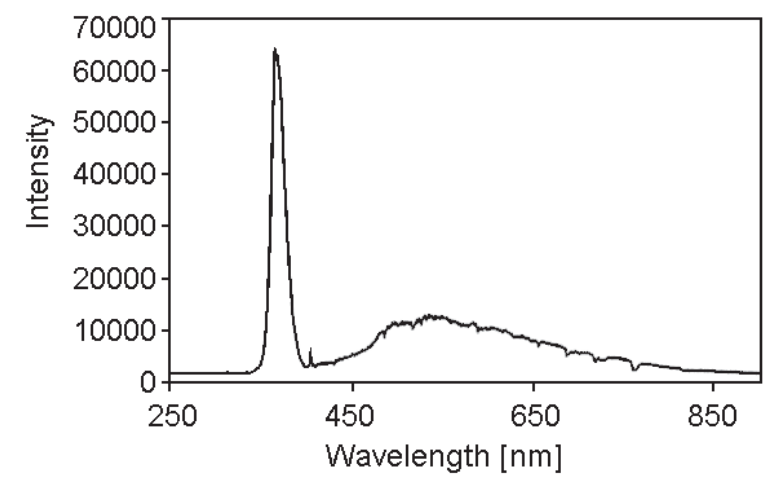

Fig. 2. Light spectrum of the lamp used for UV irradiation of the samples.

\subsection{Atomic force microscopy and scanning spreading resistance microscopy}

The surface morphology and distribution of local current were studied using atomic force microscope SolverNEXT (NT-MDT, Russia). In the case of measurement of surface morphology, AFM was operated in tapping mode at room temperature and humidity about 36 $\%$. Silicon probe for measuring in noncontact mode (NSG30) was used to obtain the images. The distribution of local current was measured in the scanning spreading resistance mode. SSRM is based on atomic force microscopy and offer two dimensional imaging of surface local current with high spatial resolution [22-26]. It is performed in contact mode with constant bias voltage applied between the conductive tip and the measured sample. The resulting current flow through the sample is measured as a function of the tip position on the surface. With the respect to the nature of sample the measurement results of SSRM depended mainly on the choice of the probe with appropriate stiffness of the cantilever, the type of the conductive tip and the value of the bias voltage applied between to the tip and the sample surface. In this case, the measurements of the electrical current distribution over the sample surface took place at the constant bias voltage $+5 \mathrm{~V}$ applied between the conductive TiNcoated silicon tip (CSG01/TiN) and measured composite. Results of the SSRM (local current maps) and AFM (contact morphology of the surface) measurements were compared in order to localize the conductive and nonconductive components or areas of the PP/graphite composites. The samples were attached into special holder intended for the measurement of conductivity. The images of local current and morphology and surface roughness were evaluated using Gwyddion software.

\subsection{X-ray diffraction analysis}

The X-ray diffraction patterns were recorded using Brucker D8 Advance diffractometer (Bruker AXS GmbH, Germany) equipped with fast position sensitive detector VÅNTEC 1 and cobalt tube $\left(\mathrm{CoK}_{\alpha}, \lambda=0.178897 \mathrm{~nm}\right)$. Measurements of all prepared samples were carried out in reflection mode in symmetrical Bragg-Brentano arrangement. The results of phase composition were evaluated using the ICDD PDF 2 Release 2014 database.

\subsection{Raman spectroscopy}

Raman spectra were measured by Raman confocal system XploRA ${ }^{\mathrm{TM}}$ (Horiba Jobin Yvon, France). Laser source $\lambda=532 \mathrm{~nm}$, grating with $1200 \mathrm{gr} . / \mathrm{mm}$ and $50 \times$ objective were used.

\subsection{FTIR spectroscopy}


This is a pre-print of an article published in Polymer Testing, 52 (2016) 46-53. The final version is available online at: https://doi.org/10.1016/j.polymertesting.2016.03.025

Mid-IR spectra were obtained by Fourier transform infrared spectrometer Nicolet 6700 (Thermo USA) using the single reflection ATR technique on a diamond crystal. Measurements were performed with a resolution of $4 \mathrm{~cm}^{-1}$ and 32 scans.

\section{Results and discussion}

\subsection{Changes in conductivity as a function of graphite filler}

Electrical conductivity depends on many factors including shape and size of filler particles distributed in polymer matrix, their physicochemical structure, processing method, conditions, etc. However, as mentioned in many studies [15,16,20,21,27], the most important parameter is a content of conductive filler in polymer composites. The macroscopic electrical conductivity of PP/graphite composite as a function of graphite content is shown in Fig. 3. In our case, the maximum conductivity $(149.5 \mathrm{~S} / \mathrm{m})$ was observed for the samples containing $75 \mathrm{wt} \% \%$ of graphite. Therefore, all thermally and UV treated samples (i.e., PP/graphite_170/1, $\mathrm{PP} /$ graphite_UV/1, PP/graphite_UV/24) were prepared from the composite containing 75 wt.\% of graphite.

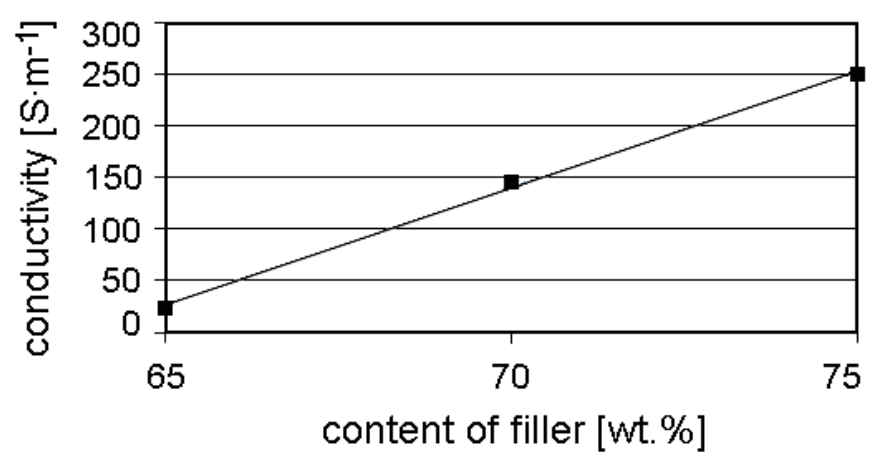

Fig. 3. Electrical conductivity values of PP/graphite nanocomposites for different content of graphite filler.

\subsection{Martens hardness}

The changes in the Martens hardness are denoted in Table 1. After the thermal and UV treatment the Martens hardness increased, especially for the PP/graphite_170/1.

Table 1

The values of Martens hardness (HM) of PP/graphite nanocomposites with 75 wt.\% of the nanofiller.

\begin{tabular}{lc}
\hline Sample HM (MPa) \\
\hline PP/graphite & 548 \\
PP/graphite_170/1 & 653 \\
PP/graphite_UV/1 & 588 \\
PP/graphite_UV/24 & 571 \\
\hline
\end{tabular}

\subsection{Changes in surface conductivity after thermal and UV treatment}

Significant decrease in conductivity was observed after the thermal and UV treatment. There was no difference between the samples after thermal (PP/graphite_170/1) and UV 
This is a pre-print of an article published in Polymer Testing, 52 (2016) 46-53. The final version is available online at: https://doi.org/10.1016/j.polymertesting.2016.03.025

(PP/graphite_UV/1, PP/graphite_UV/24) treatment and for the all composites the negligible values of conductivity $(<0.02 \mathrm{~S} / \mathrm{m})$ were measured.

Therefore, SSRM was used to study the changes in the surface conductivity of the PP/graphite composites at the nanometer scale (Fig. 4). Fig. 4a shows a current distribution across the surface of the PP/graphite composite before UV and thermal treatment. On this typical local current map the continuous conductive area with a value of current in the range of $50-80 \mathrm{nA}$ can be seen.
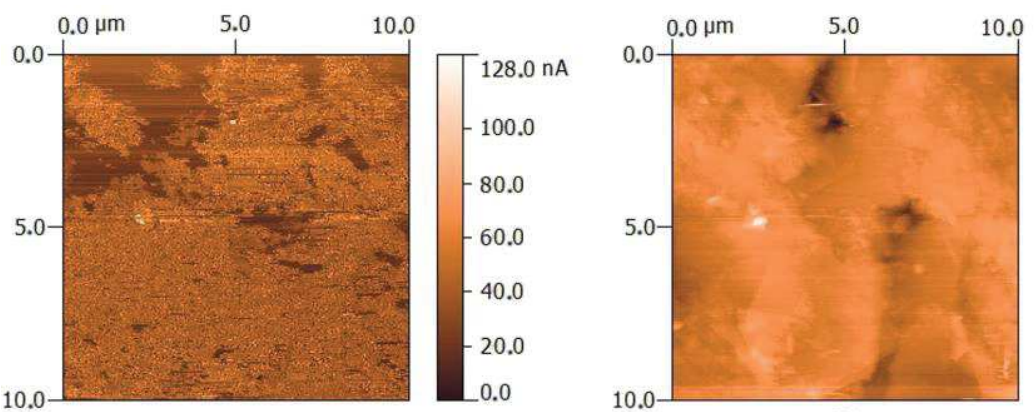

a)

b)
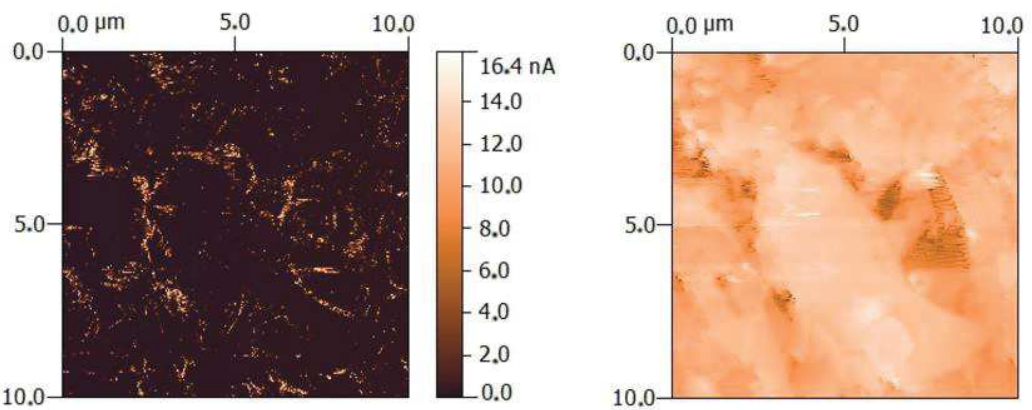

c)

d)

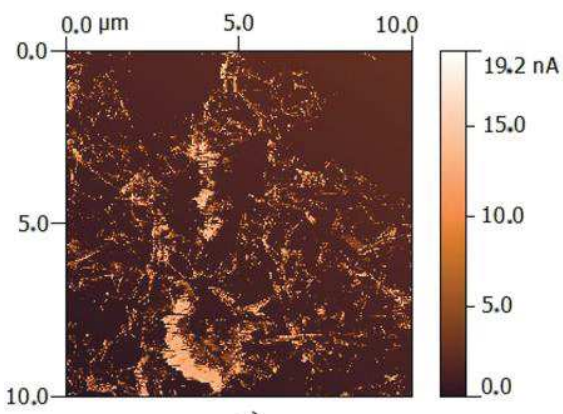

e)
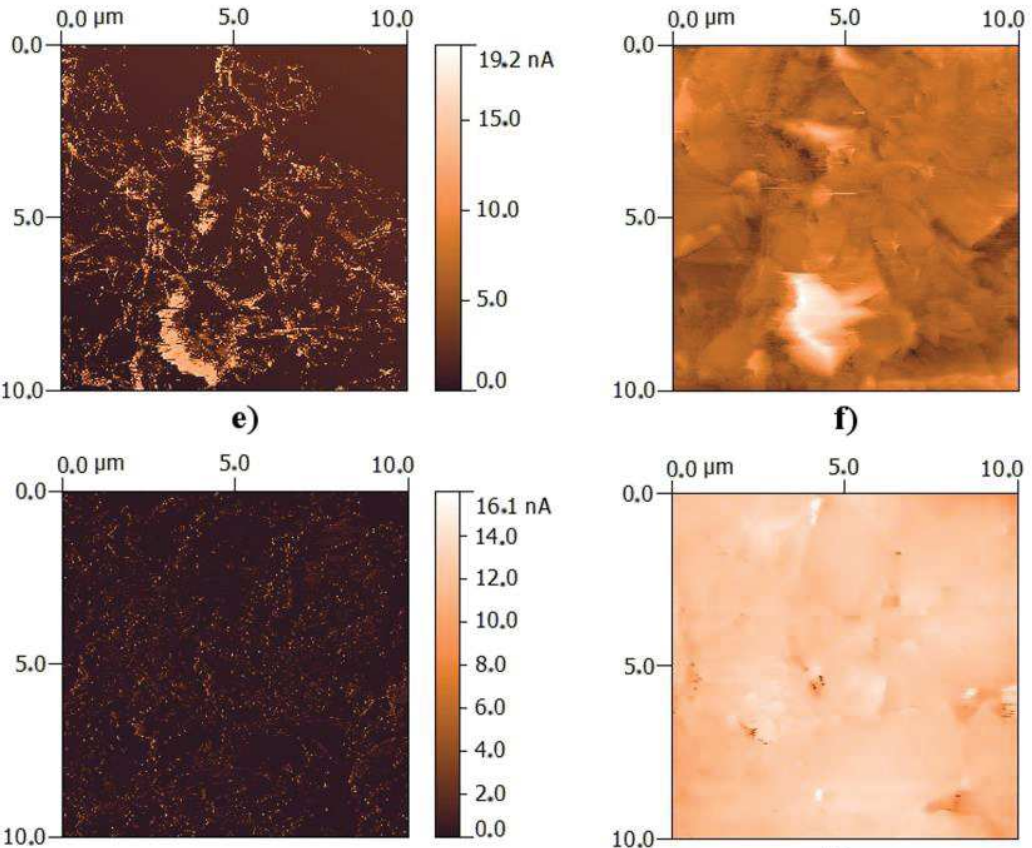

g)

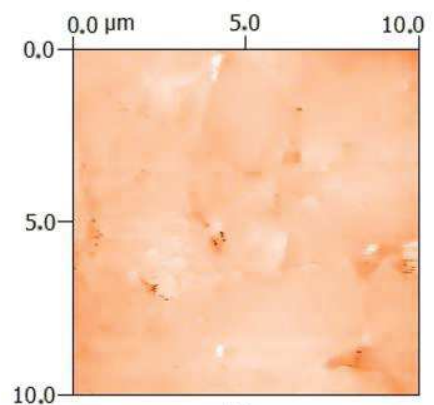

h)

Fig. 4. AFM contact mode images of PP/graphite nanocomposite with 75 wt.\% of the graphite. Original PP/graphite sample - a) local current map, b) morphology; PP/graphite_170/1 sample - c) local current map, d) morphology; PP/graphite_UV/1 sample - e) local current map, f) morphology; PP/graphite_UV/24 sample - g) local current map, h) morphology. 
After the thermal treatment (Fig. 4c) and UV irradiation (Fig. 4e and Fig. 4g) continuous areas disappeared and only the residual current on the surface is detected. There are regions with the maximum of measured current $(\approx 16-19 \mathrm{nA})$, which are separated by regions of very low current $(\approx 0.15 \mathrm{nA})$, i.e. the decrease in surface conductivity is probably connected with changes of the composite surface after the thermal and UV treatment. This is the main contrast against the local current map of the original PP/graphite before treatment. Figs. 4b, $4 \mathrm{~d}, 4 \mathrm{f}$, and $4 \mathrm{~h}$ provide the morphology of the surface measured simultaneously in contact mode.

\subsection{Morphology measurements}

In contrast to operating in contact mode, the tapping mode is not characterized by a strong tipsample mutual interaction and in the case of soft polymers and coarse-grained samples it provides much better images without visible artifacts. Three areas of each sample were scanned in tapping mode but no significant changes in the surface morphology were observed. Images of PP/graphite composite having the highest resolution are presented in Fig. 5. Plates of natural graphite can be clearly seen for all samples.

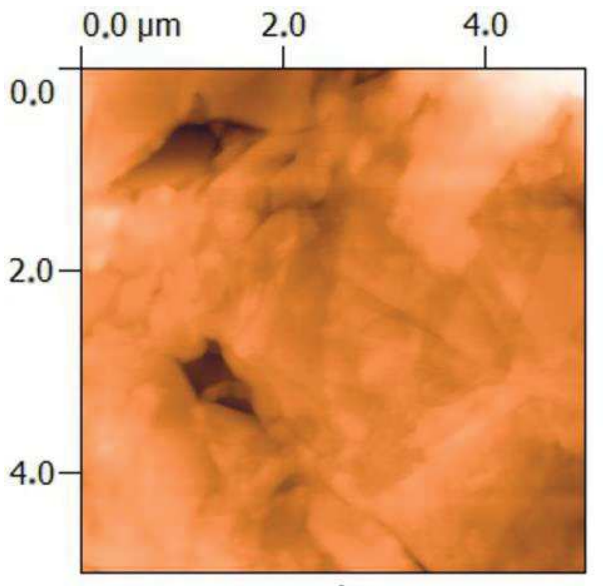

a)

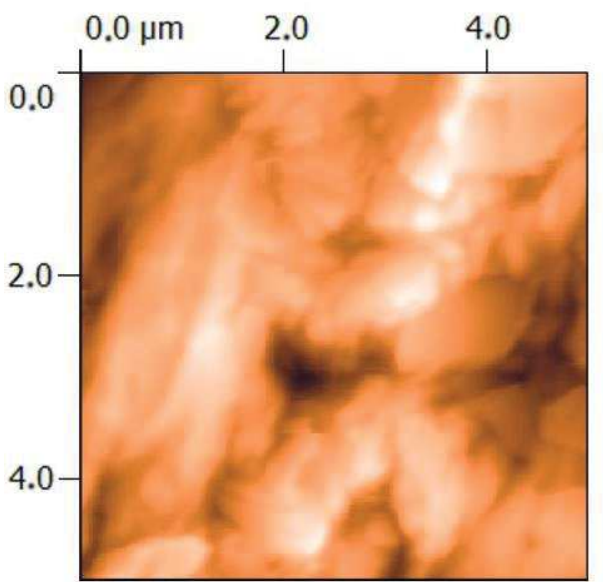

c)

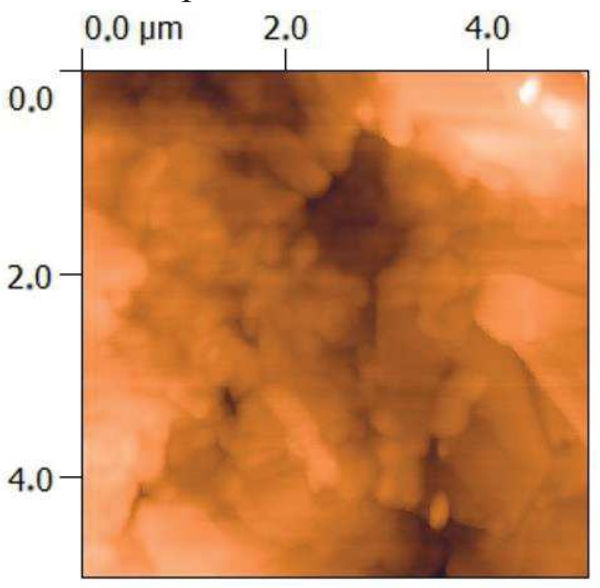

b)

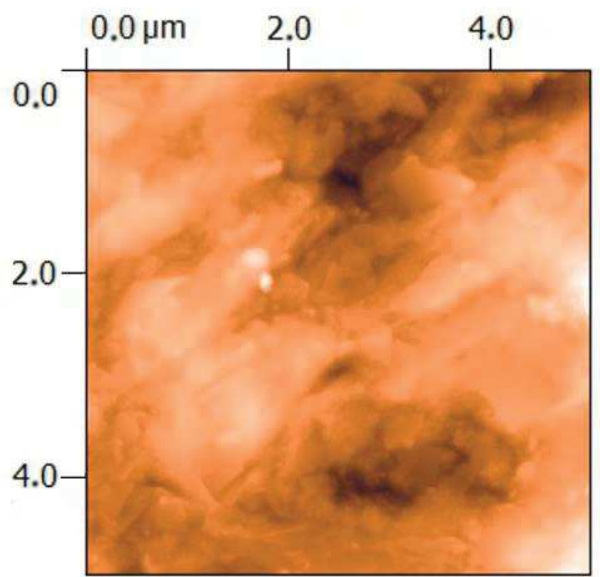

d)

Fig. 5. AFM tapping images show the surface morphology of PP/graphite nanocomposites with 75 wt. $\%$ of the graphite, a) original PP/graphite sample, b) PP/graphite_170/1 sample, c) PP/graphite_UV/1 sample, d) PP/graphite_UV/24 sample. 
This is a pre-print of an article published in Polymer Testing, 52 (2016) 46-53. The final version is available online at: https://doi.org/10.1016/j.polymertesting.2016.03.025

\subsection{Structural characterization}

XRD analysis, Raman spectroscopy, and infrared spectroscopy were used for the structural characterization of samples in order to understand the changes in conductivity.

The diffraction patterns in the Fig. 6 show the strong reflections of graphite (PDF number 020456 ) at $2 \theta \sim 28^{\circ}, 2 \theta \sim 31^{\circ}$, and $2 \theta \sim 64.6^{\circ}$ corresponding to the interlayer spacing values $\mathrm{d}=$ $0.3697 \mathrm{~nm}, \mathrm{~d}=0.3348 \mathrm{~nm}$, and $\mathrm{d}=0.1674 \mathrm{~nm}$, respectively. No exfoliation of graphite was observed.

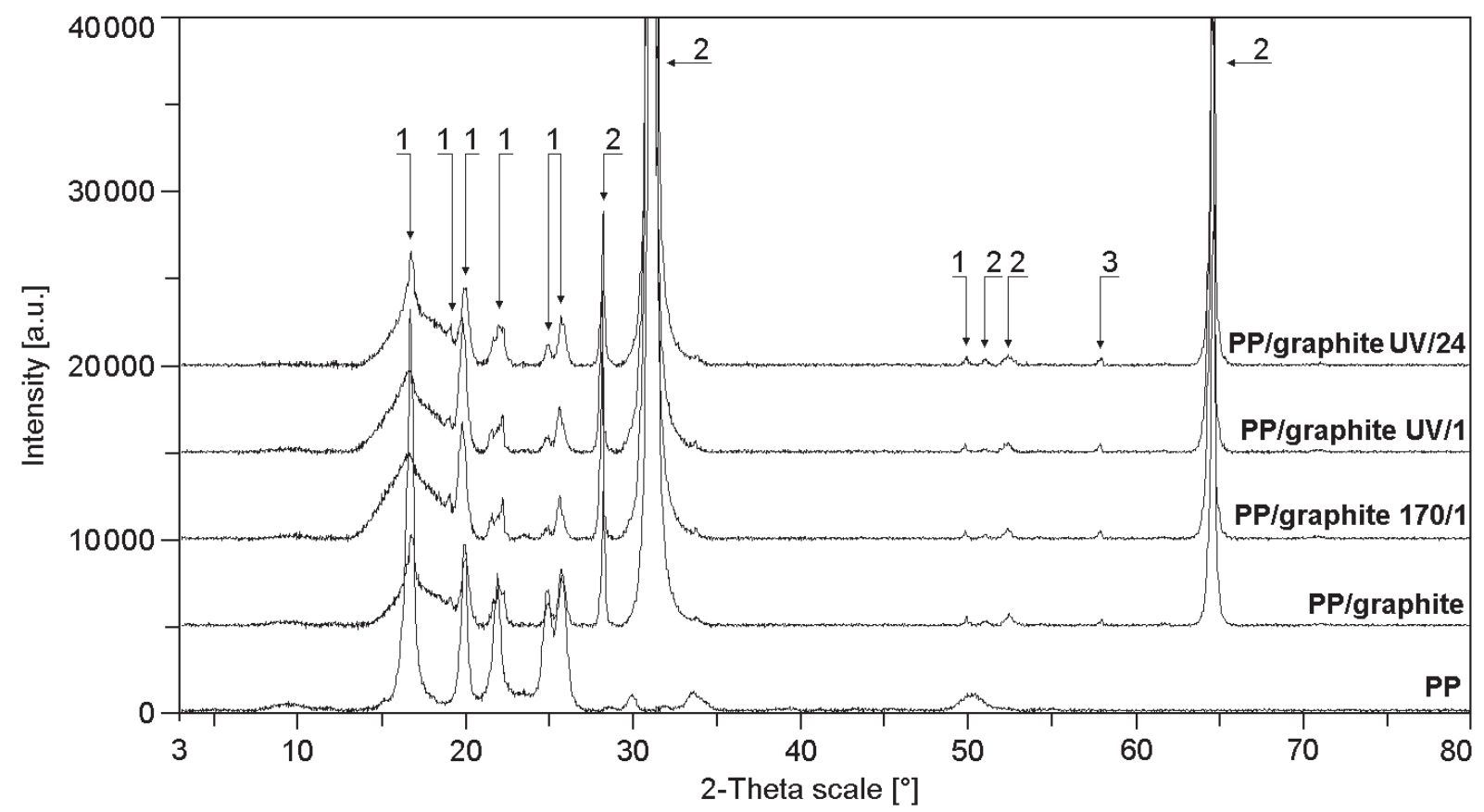

Fig. 6. X-ray diffraction patterns of pure PP and PP/graphite nanocomposites containing 75 wt.\% of graphite. 1 polypropylene, 2 - graphite, 3 - carbon.

Peaks observed at $2 \theta\left(\mathrm{CoK}_{\alpha}\right)$ angles $16.5^{\circ}, 20^{\circ}, 21.6^{\circ}, 25^{\circ}, 25.5^{\circ}$, and $50.6^{\circ}$ corresponding to (110), (040), (130), (111), (-131) and (-123) planes, respectively, are typical for PP (PDF number 59-1502). Comparison of XRD patterns of pure PP and PP/graphite composites revealed the formation of the new phase at $2 \theta \sim 58^{\circ}$. This new phase is formed during the preparation of $\mathrm{PP} /$ graphite composites and corresponds to carbon (PDF number 18-0311). Broadening and disintegration of reflections at $2 \theta$ angles $16.5^{\circ}$ and $21.6^{\circ}$ indicate the decrease in crystallinity of PP matrix after thermal and UV treatment. An overall decrease in the intensities of PP reflections is caused by the presence of strongly structured graphite.

Raman spectra of the pure PP and PP after thermal and UV treatment are shown in Fig. 7. PP spectrum shows characteristic PP bands and all these bands are visible after UV and thermal treatment. However, the intensity is much lower in the spectra after UV and thermal treatment. The lowest intensity can be found in spectrum of sample after thermal treatment (PP_170/1), but no structural changes are visible. Bands in the higher wavenumbers (2800 $3000 \mathrm{~cm}^{-1}$ ) corresponding to the $\mathrm{C}-\mathrm{H}$ asymmetric and symmetric vibrations of the $-\mathrm{CH}_{3}$ and $\mathrm{CH}_{2}$ functional groups are the most intensive. 
This is a pre-print of an article published in Polymer Testing, 52 (2016) 46-53. The final version is available online at: https://doi.org/10.1016/j.polymertesting.2016.03.025

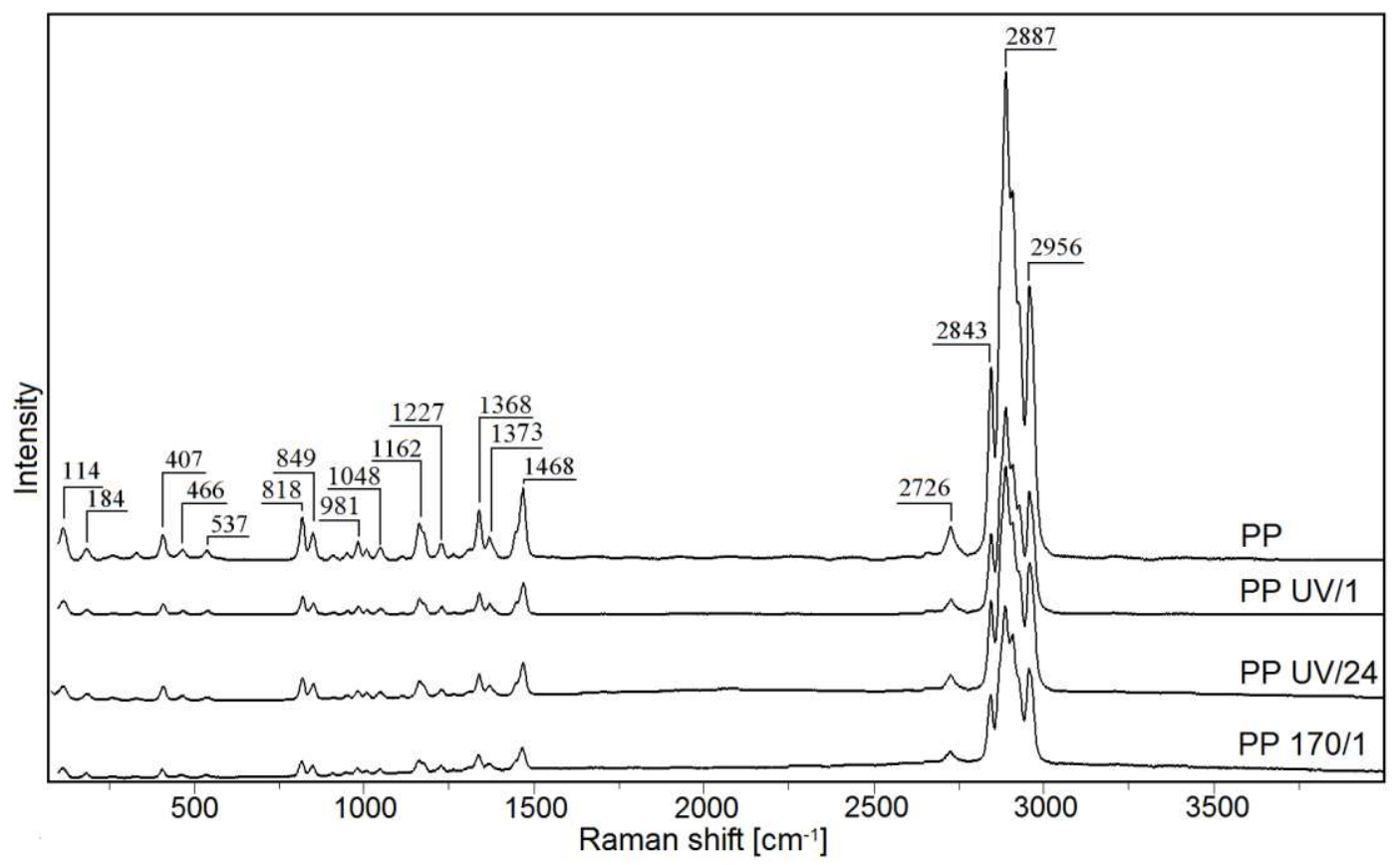

Fig. 7. Raman spectra of untreated and treated PP samples.

Raman spectra of the prepared composites PP/graphite before and after UV and thermal treatment are shown in Fig. 8.

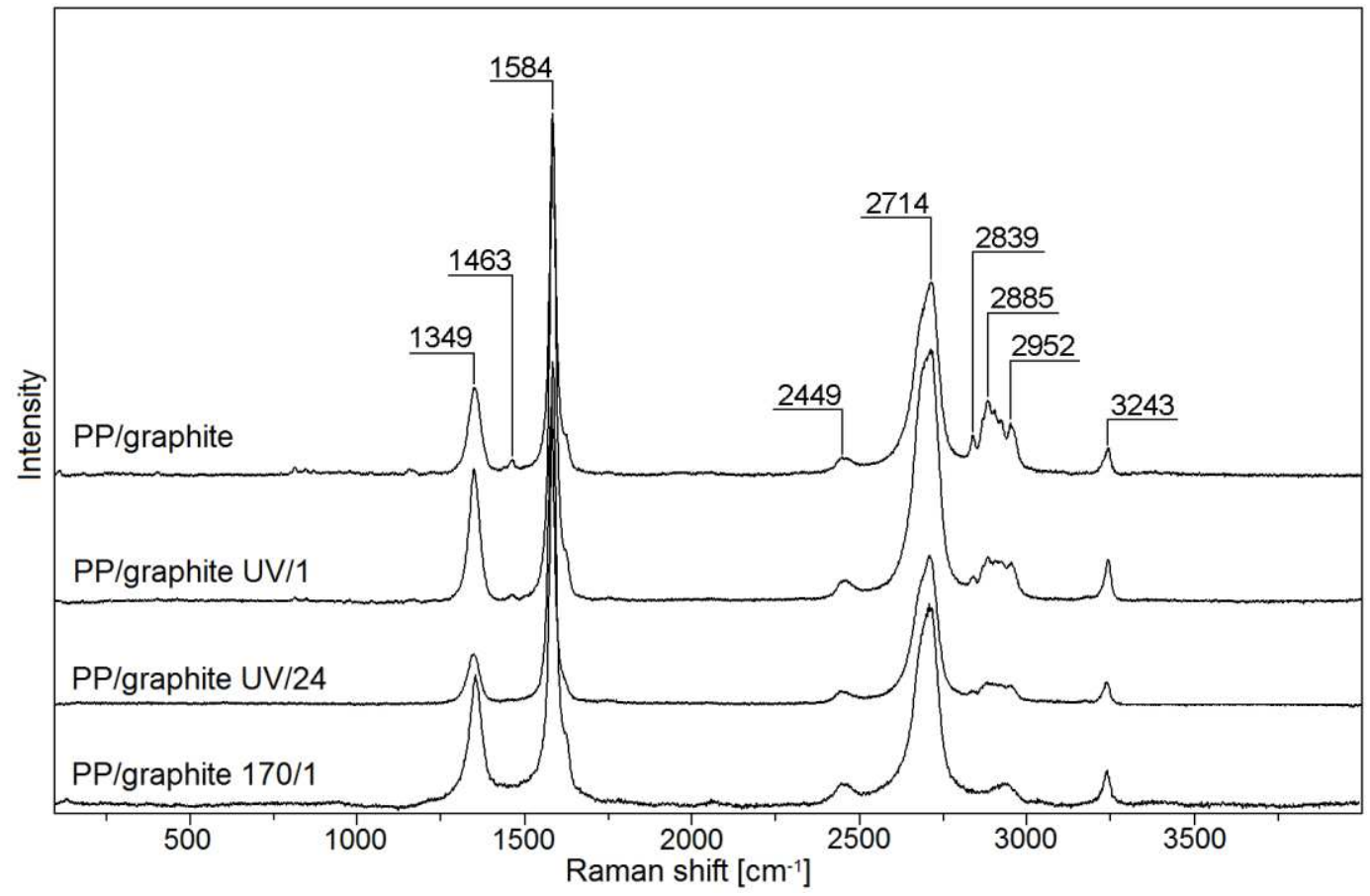

Fig. 8. Raman spectra of untreated and treated PP/graphite nanocomposites with 75 wt.\% of the graphite.

In the spectrum of the original PP/graphite composite, the most intensive bands correspond to graphite $\left(1349,1584,2449,2714\right.$ and $\left.3243 \mathrm{~cm}^{-1}\right)$. The band at $1584 \mathrm{~cm}^{-1}$ is labeled as a graphitic band ( $\mathrm{G}$ band) and another band at $2714 \mathrm{~cm}^{-1}$ (historically designated as the $\mathrm{G}^{\prime}$ band) which is the most significant band corresponding to the presence of the graphite structure $[28,29]$. Presence of G' band is caused by the second-order zone boundary phonons 
originating from a two-phonon double resonance related to the band structure of the graphene layers [30]. The band at $1349 \mathrm{~cm}^{-1}$, labeled as the disorder band (D band), indicates the presence of heteroatoms or defects within the structure. Other bands (2449 and $\left.3243 \mathrm{~cm}^{-1}\right)$ visible in the second order region correspond to the overtones and combination scattering [31]. Bands corresponding to the $\mathrm{C}-\mathrm{H}$ asymmetric and symmetric vibrations of $-\mathrm{CH}_{3}$ and $\mathrm{CH}_{2}$ functional groups of PP are also presented in the measured spectra $\left(2800-3000 \mathrm{~cm}^{-1}\right)$. Due to the higher intensity of graphite bands, PP characteristic bands are less intensive and only some of them are clearly visible $\left(1463,2839,2885\right.$ and $\left.2952 \mathrm{~cm}^{-1}\right)$ in the spectrum of original PP/graphite sample. UV treatment led to further decrease in the intensity of PP bands and in case of PP/graphite_170/1 spectrum, the PP bands are not visible at all. This corresponds to the spectrum of PP_170/1 where the intensities of the bands are the lowest. Contrary to the intensities of the PP characteristic bands, spectrum of PP/graphite UV/24 shows the lowest intensities of all graphitic bands.

In order to determine the degree of defects in graphite in dependence on the treatment, $\mathrm{I}_{\mathrm{D}} / \mathrm{I}_{\mathrm{G}}$ ratio was calculated (see Table 2), where $I_{D}$ is the intensity of the $D$ band and $I_{G}$ is the intensity of the G band. Table 2 shows that while UV treatment does not affect the structure of graphite, heat treatment resulted in significant higher rate of defects. Taking into account also the most significant decrease in intensities of PP bands in this sample (see Fig. 8), it can be concluded that the thermal treatment affects the graphite in PP/graphite composite much more than UV treatment. However, structural changes in the PP could not be observed from the Raman spectra due to the very low intensities of the PP characteristic bands.

Table 2

Quantified ratio $I_{D} / I_{G}$ for measured samples. $I_{D}$ is the intensity of $D$ band $\left(1349 \mathrm{~cm}^{-1}\right)$ and $I_{G}$ is the intensity of $G$ band $\left(1584 \mathrm{~cm}^{-1}\right)$.

\begin{tabular}{ll}
\hline Sample & $\mathrm{I}_{\mathrm{D}} / \mathrm{I}_{\mathrm{G}}$ \\
\hline original PP/graphite & $0.18 \pm 0.11$ \\
PP/graphite UV/1 & $0.13 \pm 0.11$ \\
PP/graphite UV/24 & $0.15 \pm 0.09$ \\
PP/graphite 170/1 & $0.30 \pm 0.19$
\end{tabular}

Measured FTIR spectra of the pure PP and PP after thermal and UV exposure are shown in Fig. 9. Spectrum of the PP sample shows all characteristic bands and results are similar with the Raman spectroscopy, because no structural changes are observed. However, two new bands are visible in the spectra after thermal and UV treatment, broad band about $~ 3390$ and band at $1648 \mathrm{~cm}^{-1}$ belong to $\mathrm{O}-\mathrm{H}$ bonds.

FTIR spectra of the prepared composites (Fig. 10) show only the most intensive main bands of the PP. Graphite has no visible bands in FTIR spectra and due to the high absorption the noise is higher and intensities of bands are lower (Fig. 10). At higher wavenumbers (under $3000 \mathrm{~cm}^{-1}$ ) the bands corresponding to the $\mathrm{C}-\mathrm{H}$ asymmetric and symmetric vibrations of the $\mathrm{CH}_{3}$ and $-\mathrm{CH}_{2}$ functional groups of PP [32] can be found. Other bands of PP (visible due to high intensity in the original PP spectrum) present at $1467,1377 \mathrm{~cm}^{-1}$ belong to the different 
This is a pre-print of an article published in Polymer Testing, 52 (2016) 46-53. The final version is available online at: https://doi.org/10.1016/j.polymertesting.2016.03.025

deformation vibrations of $-\mathrm{CH}_{2}$ and $-\mathrm{CH}_{3}$ groups. Contrary to the pure $\mathrm{PP}$, changes in the structure of the bands under $3000 \mathrm{~cm}^{-1}$ belonging to the symmetric stretching vibrations of the $-\mathrm{CH}_{3}$ and $-\mathrm{CH}_{2}$ functional groups are clearly visible. Also there are new bands at 1097 and $869 \mathrm{~cm}^{-1}$ belonging to the deformation vibration of $-\mathrm{CH}_{3}$ and $-\mathrm{CH}_{2}$ functional groups, which are probably connected with the changes of the stretching vibrations of the $-\mathrm{CH}_{3}$ and $-\mathrm{CH}_{2}$ functional groups under $3000 \mathrm{~cm}^{-1}$. Contrary to the Raman spectra, the lowest intensity was obtained for the sample PP/graphite UV/1.

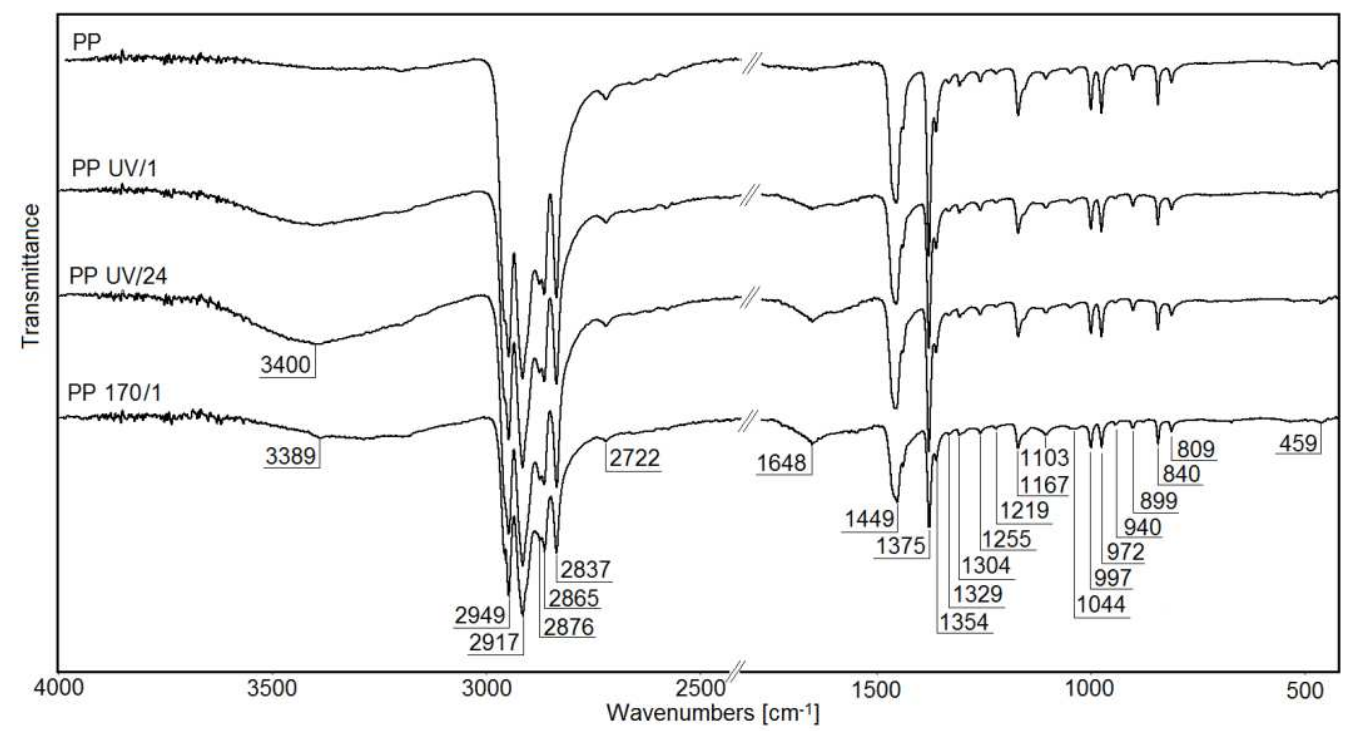

Fig. 9. FTIR spectra of untreated and treated PP samples.

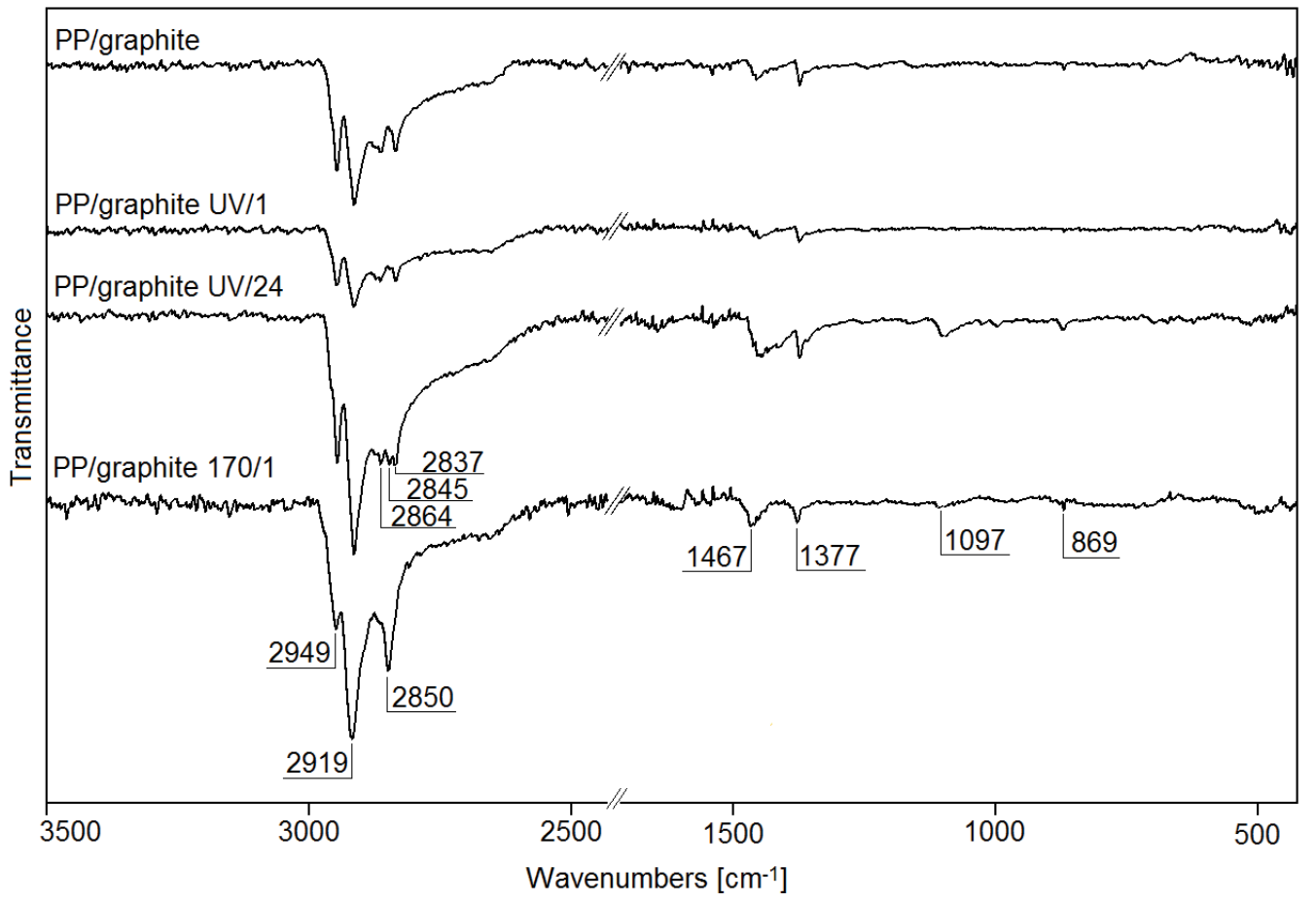

Fig. 10. FTIR spectra of untreated and treated PP/graphite nanocomposite with 75 wt.\% of the graphite. 
This is a pre-print of an article published in Polymer Testing, 52 (2016) 46-53. The final version is available online at: https://doi.org/10.1016/j.polymertesting.2016.03.025

\section{Conclusions}

Because of very good thermal and electrical conductivity, high Young's modulus and low cost, the natural graphite is widely used as an excellent reinforcing agent in composite materials designed for indoor and outdoor applications. In this study, the PP/graphite composites with different content of natural graphite were prepared and macroscopic electrical conductivities of these samples were measured and compared. The highest conductivity was observed for the composite containing $75 \mathrm{wt} \%$ of graphite filler and this composite was subsequently modified via thermal and UV treatment. The samples were annealed at $170{ }^{\circ} \mathrm{C}$ for 1 hour or UV irradiated for 1 and 24 hours. After the thermal and UV treatment the macroscopic electrical conductivity disappeared. Measurement of surface conductivity at the nanometer scale using SSRM detected the decrease in surface conductivity caused by disappearance of conductive areas on the surface of modified composites. The results clearly demonstrate that SSRM is a highly suitable technique for the characterization of the conductivity and for localization of the conductive and nonconductive components and areas of the composite. It was also observed that Martens hardness of modified samples increased, especially for the PP/graphite 170/1 sample. The surface morphology studied in tapping AFM mode did not show any significant changes as the results of thermal and UV treatment. X-ray diffraction analysis of composite with $75 \mathrm{wt} \%$ of graphite revealed the decrease in crystallinity of PP matrix after thermal and UV treatment. Raman spectroscopy showed that heat treatment resulted in higher rate of defects in graphite structure in comparison with UV treatment. Therefore, the thermal treatment affects the PP/graphite composite much more than UV treatment.

\section{Acknowledgments}

The study was supported by Ministry of Education, Youth and Sports of the Czech Republic within the project LH 12184. This work was also supported by the IT4Innovations Centre of Excellence project (CZ.1.05/1.1.00/02.0070), funded by the European Regional Development Fund and the national budget of the Czech Republic via the Research and Development for Innovations Operational Programme. The authors thank Assoc. Prof. V. Matějka for his significant help and fruitful discussions about the topic of this research. Preparation of samples by Weiwei Li and Xiaofeng Xie is highly appreciated.

\section{References}

[1] F.M. Al-Oqla, S.M. Sapuan. Natural fiber reinforced polymer composites in industrial applications: Feasibility of date palm fibers for sustainable automotive industry, J Clean Prod 2014;66:347-354.

[2] F.M. AL-Oqla, S.M. Sapuan, T. Anwer, M. Jawaid, M.E. Hoque. Natural fiber reinforced conductive polymer composites as functional materials: A review, Synth Met 2015;206:42-54.

[3] K.-Y. Lee, Y. Aitomäki, L. A. Berglund, K. Oksman, A. Bismarck. On the use of nanocellulose as reinforcement in polymer matrix composites, Compos Sci Technol 2014;105:15-27.

[4] J. Leng, X. Lan, Y. Liu, S. Du. Shape-memory polymers and their composites: Stimulus methods and applications, Prog Mater Sci 2011;56:1077-1135.

[5] S. Ramakrishna, J. Mayer, E. Wintermantel, K.W. Leong. Biomedical applications of polymer-composite materials: A review, Compos Sci Technol 2001;61:1189-1224.

[6] Y.-Y. Yu, W.-C. Chien, Y.-H. Ko, C.-P. Chen, C.-C. Chang. Preparation of conjugated polymer-based composite thin film for application in solar cell, Thin Solid Films 2015;584:363-368.

[7] N. Izzati Zulkifli, N. Samat, H. Anuar, N. Zainuddin. Mechanical properties and failure modes of recycled polypropylene/microcrystalline cellulose composites, Mater De 2015;69:114-123. 
This is a pre-print of an article published in Polymer Testing, 52 (2016) 46-53. The final version is available online at: https://doi.org/10.1016/j.polymertesting.2016.03.025

[8] J.Z. Liang, B. Li, J.Q. Ruan. Crystallization properties and thermal stability of polypropylene composites filled with wollastonite, Polym Test 2015;42:185-191.

[9] M. Prambauer, C. Paulik, C. Burgstaller. The influence of paper type on the properties of structural paper Polypropylene composites, Compos Part A Appl Sci Manuf 2015;74:107-113.

[10] W. Zhai, Y. Wang, Y. Deng, H. Gao, Z. Lin, M. Li. Recycling of asbestos tailings used as reinforcing fillers in polypropylene based composites, J Hazard Mater 2014;270:137-143.

[11] H. Gao, Y. Xie, R. Ou, Q. Wang. Grafting effects of polypropylene/polyethylene blends with maleic anhydride on the properties of the resulting wood-plastic composites, Compos Part A Appl Sci Manuf 2012;43:150-157.

[12] M. Li, X. Wen, J. Liu, T. Tang. Composites: Part A Synergetic effect of epoxy resin and maleic anhydride grafted polypropylene on improving mechanical properties of polypropylene / short carbon fiber composites, Compos Part A 2014;67:212-220.

[13] N. Roy, R. Sengupta, A.K. Bhowmick. Modifications of carbon for polymer composites and nanocomposites, Prog Polym Sci 2012;37:781-819.

[14] R. Sengupta, M. Bhattacharya, S. Bandyopadhyay, A.K. Bhowmick. A review on the mechanical and electrical properties of graphite and modified graphite reinforced polymer composites, Prog Polym Sci 2011;36:638-670.

[15] C. Garzón, H. Palza. Electrical behavior of polypropylene composites melt mixed with carbon-based particles: Effect of the kind of particle and annealing process, Compos Sci Technol 2014;99:117-123.

[16] R. Dweiri, J. Sahari. Electrical properties of carbon-based polypropylene composites for bipolar plates in polymer electrolyte membrane fuel cell (PEMFC), J Power Sources 2007;171:424-432.

[17] V. Causin, C. Marega, A. Marigo, G. Ferrara, A. Ferraro. Morphological and structural characterization of polypropylene/conductive graphite nanocomposites, Eur Polym J 2006;42:3153-3161.

[18] K. Kalaitzidou, H. Fukushima, L.T. Drzal. A new compounding method for exfoliated graphitepolypropylene nanocomposites with enhanced flexural properties and lower percolation threshold, Compos Sci Technol 2007;67:2045-2051.

[19] K. Kalaitzidou, H. Fukushima, L.T. Drzal. Mechanical properties and morphological characterization of exfoliated graphite-polypropylene nanocomposites, Compos Part A Appl Sci Manuf 2007;38:16751682.

[20] A. Király, F. Ronkay. Temperature dependence of electrical properties in conductive polymer composites, Polym Test 2015;43:154-162

[21] I. Tchmutin, A.T. Ponomarenko, E.P. Krinichnaya, G.I. Kozub, O.N. Efimov. Electrical properties of composites based on conjugated polymers and conductive fillers, Carbon 2003;41:1391-1395.

[22] G. Benstetter, R. Biberger, D. Liu. A review of advanced scanning probe microscope analysis of functional films and semiconductor devices, Thin Solid Films 2009;517:5100-5105.

[23] P. De Wolf, E. Brazel, A. Erickson. Electrical characterization of semiconductor materials and devices using scanning probe microscopy, Mater Sci Semicond Process 2001;4:71-76.

[24] S. Doering, R. Rudolf, M. Pinkert, H. Roetz, C. Wagner, S. Eckl, et al.. Scanning spreading resistance microscopy for failure analysis of nLDMOS devices with decreased breakdown voltage, Microelectron Reliab 2014;54:2128-2132.

[25] C. Jiang, I.L. Repins, C. Beall, H.R. Moutinho, K. Ramanathan. Solar energy materials \& solar cells investigation of micro-electrical properties of $\mathrm{Cu}_{2} \mathrm{ZnSnSe}_{4}$ thin films using scanning probe microscopy, Sol Energy Mater Sol Cells 2015;132:342-347.

[26] M. Truchlý, T. Plecenik, O. Krško, M. Gregor, L. Satrapinskyy, T. Roch, B. Grančič, M. Mikula, A. Dujavová, Š. Chromik, P. Kúš, A. Plecenik. Studies of $\mathrm{YBa}_{2} \mathrm{Cu}_{3} \mathrm{O}_{6}{ }^{+{ }^{+x}}$ degradation and surface conductivity properties by scanning spreading resistance microscopy, Phys C Supercond Its Appl 2012;483:61-66.

[27] V.S. Mironov, J.K. Kim, M. Park, S. Lim, W.K. Cho. Comparison of electrical conductivity data obtained by four-electrode and four-point probe methods for graphite-based polymer composites, Polym Test 2007;26:547-555.

[28] A.C. Ferrari. Raman spectroscopy of graphene and graphite: Disorder, electron-phonon coupling, doping and nonadiabatic effects, Solid State Commun 2007;143:47-57. 
This is a pre-print of an article published in Polymer Testing, 52 (2016) 46-53. The final version is available online at: https://doi.org/10.1016/j.polymertesting.2016.03.025

[29] A.C. Ferrari, J.C. Meyer, V. Scardaci, C. Casiraghi, M. Lazzeeri, F. Mauri, S. Piscanec, D. Jiang, K.S. Novoselov, S. Roth, A.K. Geim. Raman spectrum of graphene and graphene layers, Phys Rev Lett 2006;97:187401.

[30] S. Bose, T. Kuila, A.K. Mishra, N.H. Kim, J.H. Lee. Preparation of non-covalently functionalized graphene using 9-anthracene carboxylic acid, Nanotechnology 2011;22:405603.

[31] R.J. Nemanich, S.A. Solin. First- and second-order Raman scattering from finite-size crystals of graphite, Phys Rev B 1979;20:392-401.

[32] W. Urbaniak-Domagal. Advanced aspects of spectroscopy, Chapter 3: The use of the spectrometric technique FTIR-ATR to examine the polymers surface, ISBN 978-953-51-0715-6. 